\title{
Investigation on the Catalytic Behavior of Fe Loaded on Encapsulated Titanium for Sonocatalytic Degradation of Amaranth: Characterization and Reusability Study
}

\author{
Atheel Hassan Alwash ${ }^{1,2^{*}}$, Ahmed Zuhairi Abdullah ${ }^{1}$, Norli Ismail ${ }^{3}$ \\ ${ }^{1}$ School of Chemical Engineering, Universiti Sains Malaysia, Penang, Malaysia \\ ${ }^{2}$ Department of Chemistry, College of Science, Al-Nahrain University, Baghdad, Iraq \\ ${ }^{3}$ School of Industrial Technology, Universiti Sains Malaysia, Penang, Malaysia \\ Email: *atheel_eng78@yahoo.com
}

Received March 6, 2013; revised April 11, 2013; accepted May 9, 2013

Copyright (C) 2013 Atheel Hassan Alwash et al. This is an open access article distributed under the Creative Commons Attribution License, which permits unrestricted use, distribution, and reproduction in any medium, provided the original work is properly cited.

\begin{abstract}
The present study addressed the properties affecting the activity of a new heterogeneous catalyst Fe/Ti-NaY in the ultrasonic irradiated for decolorization of amaranth dye in aqueous solution. The catalyst was prepared by the ion exchange and impregnation method. Different characterization techniques, i.e. XRD, AFM, TEM and SEM/EDAX were done to characterize the properties of the fresh and used catalyst. This catalyst was able to keep its stability and high activity without any noticeable reduction in the decolorization efficiency of amaranth after three cycles of reaction. The $\mathrm{X}$-ray diffraction proved the high stability and the crystallinity for the reuse catalyst. The COD removal for the fresh and used catalyst with and without calcination was $57 \%, 36 \%$ and $20 \%$ respectively. The hydrophilic properties of the heterogeneous catalyst increased slightly due to the loading of Ti and Fe ions.
\end{abstract}

Keywords: Stability of Catalyst; Hydrophilic Properties; Sonocatalytic Degradation; Amaranth

\section{Introduction}

In the recent years, sonocatalytic degradation for waste water treatment was considered as a novel technology. Ultrasonic waves have the ability to decompose water molecules into extremely reactive hydrogen atoms $\left(\mathrm{H}^{+}\right)$ and hydroxyl radicals $\left(\mathrm{OH}^{*}\right)$ by the heat generated from the cavity implosion. This cavity implosion is responsible for the high localized temperature and pressure inside the bubble. Commonly, the generation of highly reactive species such as hydroxyl $\left(\mathrm{OH}^{*}\right)$, hydrogen $\left(\mathrm{H}^{*}\right)$, hydroperoxyl $\mathrm{OH}_{2}{ }_{2}$ radicals and hydrogen peroxide is achieved under these extreme conditions [1]. However, the efficiency of sonolysis process is still not sufficient alone and cannot be used in the practical treatment of refractory organic pollutants, due to its limited degradation rate [2]. Therefore, there is the necessity to use a heterogeneous catalyst combined with ultrasonic irradiation to increase the activity of the process [3].

The synergetic effect between ultrasound irradiation and heterogeneous catalyst provides advantages in addition to the formation of radical species.

"Corresponding author.
The ultrasonic process offers clean reactive surfaces for the catalyst during the reaction by the removal of reactive intermediates or by-products from the catalyst surface. In addition, the division of the catalyst into small particles offers a higher surface area maintained to allow higher mass transfer which considered as the main advantages of ultrasound system over other AOPs [4].

Titanium dioxide is one of the most efficient photocatalysts owing to its high stability, super hydrophilic properties and its low cost. However, it has poor catalytic activity when used alone due to the fast charge carrier recombination in addition to the recycling difficulties [5]. Therefore there is a need to overcome these drawbacks by doping metals to increase the activity of titanium oxide [6]. Different reports have been attempted dealing with the modification of bare $\mathrm{TiO}_{2}$ e.g. Jamalluddin and Abdullah [7], Wang et al. [8], Pang and Abdullah [9] and Zhu et al. [10] and many other successful reports all concluded that the modified $\mathrm{TiO}_{2}$ show significant enhancement in sonocatalytic activity for the degradation of dyes comparing to the unmodified $\mathrm{TiO}_{2}$. Furthermore, the use of adsorbents to act as supports for $\mathrm{TiO}_{2}$ particles such as zeolite was another solution to solve the draw- 
backs of bare $\mathrm{TiO}_{2}$. Different advantages have been obtained from the loading of $\mathrm{TiO}_{2}$ on zeolite i.e. increasing the concentration of $\mathrm{TiO}_{2}$ without the problems of aggregation especially at higher concentration, uncomplicated separation or filtration process, the adsorption of intermediate products that are produce after the reaction, the ability to concentrate the pollutants near $\mathrm{TiO}_{2}$ particles and recyclability of the catalyst [11].

Therefore in this study, the co-loading of both Fe and Ti with the framework of zeolite will give the chance to occupymost of the internal and external surface areas of zeolite with active metals thus enhance the catalytic activity. Furthermore, the synergistic between Fe and encapsulated $\mathrm{TiO}_{2}$ can retard the recombination between $\mathrm{e}^{-}-\mathrm{h}^{+}$ pair generated from the irradiated $\mathrm{TiO}_{2}$ nano particles by ultrasonic and solve the problems of separation and reusability which consequently improve the catalytic activity. The main goal of this research was to characterize the fresh and reused catalyst and to investigate the reusability and stability of this catalyst for the degradation of amaranth after many consecutive cycles under ultrasonic reaction. In addition, to the investigation of hydrophilic/hydrophobic properties of the produced catalyst that appreciably affected its activity after the doping of those metals.

\section{Experimental}

\subsection{Materials}

H-Y zeolite with Si/Al 15 was obtained from Zeolyst International; Amaranth dye (content 90\%) purchased from Sigma and was used without further purification. Meanwhile, other chemical such as potassium titanooxalate dehydrate was obtained from Sigma-Aldrich, sodium chloride was supplied by J. T. Baker, Iron (III) nitrate nonhydrate was obtained from Merck Sdn. Bhd, hydrogen peroxide (35\%) was supplied by R\& M Chemicals. The Di-water, purified with an Elga-Pure Water Purification system, was used for preparing of all solutions in this study.

\subsection{Preparation Method}

\subsubsection{Preparation of NaY}

The dried H-Y zeolite was converted to the sodium form by means of an ion exchange method [12]. The zeolite was first washed with $1 \mathrm{M} \mathrm{NaCl}$ at $80{ }^{\circ} \mathrm{C}$ for $4 \mathrm{~h}$ in such a way that the ratio of zeolite to sodium chloride solution was 1:80. The slurry was then filtered and washed with deionized water to remove the excess amount of $\mathrm{NaCl}$. In order to get complete exchange of sodium into zeolite, the procedure was repeated twice. The sample was then dried over night at a temperature of $80^{\circ} \mathrm{C}$ and then calcined in a muffle furnace at $550^{\circ} \mathrm{C}$ for $5 \mathrm{~h}$.

\subsubsection{Preparation of $\mathrm{TiO}_{2}$ Encapsulated into Na-Zeolite}

$\mathrm{TiO}_{2}$ modified NaY was prepared using similar procedure as reported by Liu et al. [13]. Different concentrations of potassium titanooxalate $\left(0.56-2.823 \times 10^{-2}\right.$ $\mathrm{mol} / \mathrm{L}$ ) solution was prepared in $100 \mathrm{~mL}$ water. One gram of support (Na-Y) was added to each concentration and stirred for $12 \mathrm{~h}$. After the ion exchange step, the catalyst was filtered with membrane filter $(0.45 \mu \mathrm{m}$ pore size) and then washed with excessive amount of water to avoid the physically adsorbed titanium species from aggregating on the external surface of zeolites then followed by drying overnight in an oven at $100^{\circ} \mathrm{C}$. The above procedure was repeated twice to achieve higher loading of titanium and the catalysts were denoted as $\mathrm{Ti}_{1}-\mathrm{NaY}, \mathrm{Ti}_{2}-\mathrm{NaY}, \mathrm{Ti}_{3}-\mathrm{NaY}$ and $\mathrm{Ti}_{4}-\mathrm{NaY}$ according to the increasing titanium amount in the catalyst. After the calcination step of the samples at $550^{\circ} \mathrm{C}$ for $5 \mathrm{~h}$ with a heating rate $5 \mathrm{~K} / \mathrm{min}$, they were ground into fine powder and kept in a dry cabinet.

\subsubsection{Preparation of $\mathrm{Fe}(\mathrm{III}) / \mathrm{Ti}_{4}-\mathrm{NaY}$ by Impregnation Method}

The higher loading of titanium $\mathrm{Ti}_{4}-\mathrm{NaY}$ was chosen as a support for the loading of Fe ions ranging from $(0.2-1.0)$ $\mathrm{wt} \%$. Fe (III) $/ \mathrm{Ti}_{4}-\mathrm{NaY}$ catalyst was prepared using wet impregnation method. Different $w \mathrm{t} \%$ of Fe (III) nitrate was dissolved in $100 \mathrm{~mL}$ deionized water and then a known amount of $\mathrm{Ti}_{4}-\mathrm{NaY}$ catalyst was added into the solution and mixed for $24 \mathrm{~h}$ at room temperature. After mixing was completed the solution was evaporated using water bath at $100^{\circ} \mathrm{C}$ under continuous stirring. The obtained catalysts were dried over night at $100^{\circ} \mathrm{C}$ and then calcined at $500^{\circ} \mathrm{C}$ for $4 \mathrm{~h}$. The final obtained catalysts were named according to the different Fe loading onto $\mathrm{Ti}_{4}-\mathrm{NaY}$ such as $0.2 \% \mathrm{Fe} / \mathrm{Ti}_{4}-\mathrm{NaY}, 0.4 \% \mathrm{Fe} / \mathrm{Ti}_{4}-\mathrm{NaY}$, $0.6 \% \mathrm{Fe} / \mathrm{Ti}_{4}-\mathrm{NaY}, 0.8 \% \mathrm{Fe} / \mathrm{Ti}_{4}-\mathrm{NaY}$ and $1.0 \% \mathrm{Fe} / \mathrm{Ti}_{4}-$ $\mathrm{NaY}$.

\subsection{Characterization of Catalyst}

The characterization of the catalysts with different analytical techniques was performed on the titanium encapsulated into $\mathrm{Na}-\mathrm{Y}$. The reflectance of the solid samples was determined using UV-VIS spectrophotometer (Perkin Elmer Lambda 35) with wavelengths from 190 $1100 \mathrm{~nm}$. The transmittance electron microscopy (TEM) imaging was equipped with an image analyzer and operated at $120 \mathrm{Kv}$. The roughness of the catalyst surface was checked using SPA 400 AFM technique. Meanwhile X-ray diffraction patterns were obtained using XRD (Philips Goniometer PW 1820 diffractometer) method and the surface morphology was studied using SEM unit (Oxford INCA/ENERGY-350) with energy dispersive 
X-ray analysis (EDAX) system for both fresh and used catalysts.

\subsection{Sonocatalytic Reaction}

All experiments were carried out in $100 \mathrm{~mL}$ cylindrical vessels and they were placed in an ultrasonic water bath with an output power fixed at $50 \mathrm{~W}$ and an ultrasonic frequency of $40 \mathrm{KHz}$. for $2 \mathrm{~h}$. Before the sonocatalytic reaction was started, the solution was stirrer for $30 \mathrm{~min}$ at room temperature to maintain a good dispersion of catalyst with the dye solution and to allow any possible adsorption of the dye on the catalysts.

The catalytic activity was examined by calculating the decolorization efficiency of amaranth using a UV-vis spectrophotometer. During the reaction, $7 \mathrm{ml}$ of solution was withdrawn at each interval time and centrifuged using Kubota 5910 centrifuge to separate the supernatant and the catalyst particles. Then, concentration of the dye solution was determined at a maximum absorbance wavelength of $521 \mathrm{~nm}$. The decolorization efficiency and the COD removal of the catalyst were calculated according to the following equations:

$$
\begin{aligned}
& \text { Decolorization efficiency } \%=\left[1-\frac{\mathrm{C}_{\mathrm{t}}}{\mathrm{C}_{\mathrm{o}}}\right] \times 100 \\
& \mathrm{COD} \text { removal } \%=\left[1-\frac{\mathrm{COD}_{\mathrm{t}}}{\mathrm{COD}_{\mathrm{o}}}\right] \times 100
\end{aligned}
$$

where $\mathrm{C}_{\mathrm{o}}(\mathrm{mg} / \mathrm{L})$ is the initial concentration of dye, $\mathrm{Ct}$ $(\mathrm{mg} / \mathrm{L})$ is the concentration of dye at certain reaction time, $t$ (min). While $\mathrm{COD}_{\mathrm{o}}$ (ppm) is the initial COD of the dye, $\operatorname{COD}_{t}(\mathrm{ppm})$ is the COD of the dye at certain reaction time, $\mathrm{t}(\mathrm{min})$.

\section{Results and Discussion}

\subsection{Characterization of Catalyst}

\subsubsection{UV-Vis Reflectance Spectra}

The UV-vis reflection spectra were carried out for the parent $\mathrm{NaY}$, encapsulated $\mathrm{TiO}_{2}\left(\mathrm{Ti}_{4}-\mathrm{NaY}\right), \mathrm{Fe} / \mathrm{Ti}_{4}-\mathrm{NaY}$ with that of bare $\mathrm{TiO}_{2}$ as reference and the results are shown in Figure 1. A Blue shift was observed towards shorter wave lengths about $372 \mathrm{~nm}$ for the $\mathrm{Ti}_{4}-\mathrm{NaY}$ compared to the bare $\mathrm{TiO}_{2}$ that had a wave length of about $390 \mathrm{~nm}$. The provenance of such blue shift towards shorter wave length was due to the quantum size effect for semiconductors as the particle size slightly decreased after the incorporation of $\mathrm{TiO}_{2}$ into the pores of the zeolite. Easwaramoorthi and Natarajan [15] investigated the difference in UV-vis spectra for both titanium oxide anchored at the surface of zeolite or encapsulated into the pores of it and the results showed that $\mathrm{TiO}_{2}$ anchored at the surface of zeolite showed red shift towards higher wave length while the $\mathrm{TiO}_{2}$ encapsulated into zeolite

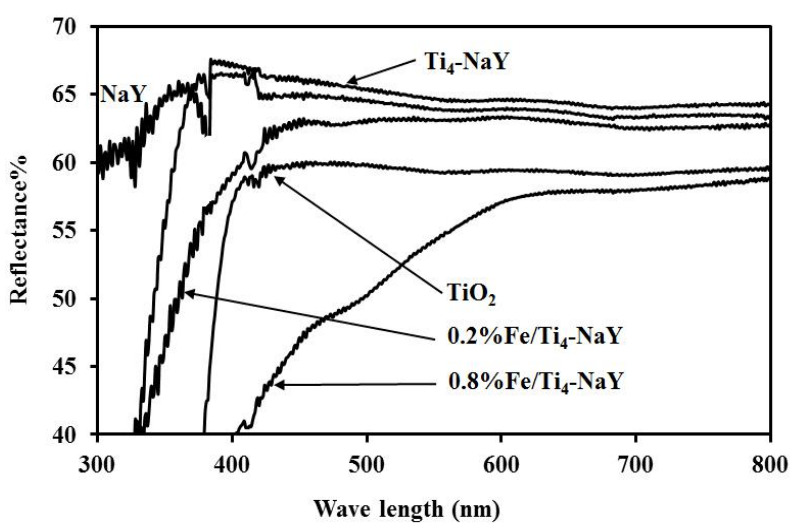

Figure 1. The reflection spectra of bare $\mathrm{TiO}_{2}, \mathrm{NaY}, \mathrm{Ti}_{4}-\mathrm{NaY}$ and $\mathrm{Fe} / \mathrm{Ti}_{4}-\mathrm{NaY}$.

showed a blue shift towards shorter wave length. In contrary to $\mathrm{Ti}_{4}-\mathrm{NaY}$, the unmodified $\mathrm{NaY}$ support did not show any decrease in its reflectance spectra however after encapsulation titanium into the NaY a sharp decrease in the reflectance spectra was detected due to the presence of $\mathrm{TiO}_{2}$ into the samples. Joshi et al. [16] reported that the sudden fall in the reflection spectra indicates the presence of optical band gap in these samples.

As the catalyst $\mathrm{Ti}_{4}-\mathrm{NaY}$ was considered as a support for the loading of $\mathrm{Fe}$ due to the higher amount of titanium into NaY. The loading of Fe (III) ions into the $\mathrm{Ti}_{4}-\mathrm{NaY}$ showed a red shift towards higher wave length from $400-600 \mathrm{~nm}$ for different loadings of $\mathrm{Fe}$ (III), i.e. $0.2,0.4,0.6,0.8$ and $1.0 \mathrm{wt} \%$ compared to the $\mathrm{Ti}_{4}-\mathrm{NaY}$ which showed a wave length of about $372 \mathrm{~nm}$. The shift towards higher wave length caused an enhancement in the absorption of light at the visible region signifying the improvement in the band gap energy of the catalyst. This enhancement was ascribed to the excitation of $3 \mathrm{~d}$ electrons from the Fe doping ions to the conduction band of $\mathrm{Ti}_{4}-\mathrm{NaY}$ [17]. Wu et al. [18] reported that a red shift was observed in the diffuse reflectance spectra for the $\mathrm{TiO}_{2}$ after the doping with $0.5 \% \mathrm{Fe}$ ions.

The energy gaps for the bare $\mathrm{TiO}_{2}, \mathrm{TiO}_{2}$ encapsulated into $\mathrm{NaY}$ and $\mathrm{Fe} / \mathrm{Ti}_{4}-\mathrm{NaY}$ were calculated from their reflection spectra obtained from the UV-vis analysis. The energy gaps were found to decrease from $3.7 \mathrm{eV}$ for $\mathrm{Ti}_{4}$ $\mathrm{NaY}$ to 3.5, 3.3, 2.9, 2.8 and $2.8 \mathrm{eV}$ for $(0.2-1.0) \mathrm{wt} \%$ of Fe. At higher concentration of Fe, i.e. $1.0 \mathrm{wt} \%$, no significant decrease in the energy gap was observed.

This indicated that there was an optimum value for the doping of ions and above this optimum loading value the optical gap showed no more dependence on the metal ions. Gúth, S. R. Lukič [19] suggest that increasing the Fe content above $1 \%$ makes the $\mathrm{Fe}$ ions present as a separate center which weakly interacts with the structure of material as a result $\mathrm{Fe}$ content above $1 \%$ will have no effect on the energy gap pattern. 


\subsubsection{Transmittance Electron Microscopy (TEM)}

In order to investigate the position of the loaded metals i.e. $\mathrm{TiO}_{2}$ and $\mathrm{Fe}$ with respect to zeolite structure either encapsulated into zeolite structure or exist at the external surface of it, the TEM images were taken for NaY, titanium encapsulated into $\mathrm{NaY}\left(\mathrm{Ti}_{4}-\mathrm{NaY}\right)$ and $\mathrm{Fe}$ loaded onto encapsulated titanium $\left(0.8 \% \mathrm{Fe} / \mathrm{Ti}_{4}-\mathrm{NaY}\right)$ catalyst as in Figure 2. The TEM images in Figure 2(a) at magnification of $45 \mathrm{~K}$ present the $\mathrm{NaY}$ structure before the loading of any metals and no dark spots where detected with its crystalline. However, there were dark and light spots that were distinguished at the outside and the inner side of the nanoporous structure as shown in image (b and c) at $45 \mathrm{k}$ magnification. The appearance of small spot in Figure 2(b) was ascribed to existence of $\mathrm{TiO}_{2}$ clusters between the crystal lattice of zeolite, in other word shielded by the zeolite structure (Ti has heavier molecular weight than $\mathrm{Si}$ and $\mathrm{Al}$ elements which is the main composition of zeolite). However, it was difficult to determine the accurate size of $\mathrm{TiO}_{2}$ due to the overlapping of $\mathrm{TiO}_{2}$ crystallites within the matrix of the zeolite.

On other hand, in Figure 2(c) the dark spots at the outer edge of the zeolite particle were ascribed to $\mathrm{Fe}$ metal although its detection was very difficult due to the well dispersion or low loading. These dark spots were ascribed to the higher molecular weight of Fe metals comparing to that of titanium. Thus, the TEM image of the former gave more dark spots than the encapsulated titanium.

\subsubsection{AFM Analysis}

The AFM technique was used to investigate the effect of loading of $\mathrm{Ti}$ and $\mathrm{Fe}$ metals on the surface uniformity of the catalyst. Figure 3 shows the three dimensional (3-D), two dimensional (2-D) AFM images for $\mathrm{NaY} \mathrm{Ti}_{4}-\mathrm{NaY}$ and $0.8 \% \mathrm{Fe} / \mathrm{Ti}_{4}-\mathrm{NaY}$. It was noticed that both the $\mathrm{NaY}$ and $\mathrm{Ti}_{4}-\mathrm{NaY}$ surface had approximately the same roughness value around $74 \mathrm{~nm}$. This similarity in the roughness of the catalyst surface before and after the loading of titanium was attributed to the absence of $\mathrm{TiO}_{2}$ from the surface of the catalyst. Instead, it was mainly encap- sulated into the pores of the zeolite. These results were in agreement with the results of UV-vis technique. Meanwhile for the loading of Fe (III), the roughness of the catalyst was found to reduce drastically to $28 \mathrm{~nm}$. This reduction in the roughness of the catalyst surface could be attributed to the well dispersion of Fe oxide (formed after the calcination step) or due to its small particle sizes.

From the above discussion it was clear that the loading of metals and the existence of theme on the surface or inside the pores of zeolite affected the roughness of the catalyst. The existence of the $\mathrm{Fe}$ oxide that wasformed after the calcination step seemed to be affecting the uniformity on the catalyst surface.

\subsection{The Sonocatalytic Activity of Catalyst for Decolorization of Amaranth}

The actual amount of the Ti species encapsulated into zeolite using the ion exchange method was checked by the ICP analysis and the $\mathrm{Ti}_{4}-\mathrm{NaY}$ catalyst showed the higher amount of Ti with $2.973 \mathrm{mg} \cdot \mathrm{g}^{-1}$. Therefore the $\mathrm{Ti}_{4}-\mathrm{NaY}$ was used as a template in this study for the doping of $\mathrm{Fe}$ ions from $(0.2-1.0) \mathrm{wt} \% \mathrm{Fe}$.

The effect of Fe (III) ions was subsequently investigated for the decolorization of amaranth using different loadings $(0.2-1.0) \mathrm{wt} \%$ of $\mathrm{Fe}$ (III) onto $\mathrm{Ti}_{4}-\mathrm{NaY}$. The activity of the catalyst was found to increase from $38 \%$, $57 \%$ and $60 \%$ for $0.2,0.4$ and $0.6 \mathrm{wt} \%$, respectively reaching its maximum activity of $75 \%$ with $0.8 \mathrm{wt} \% \mathrm{Fe}$ loading and the results are shown in Figure 4. Increasing the sonocatalytic activity of $0.8 \mathrm{wt} \% \mathrm{Fe} / \mathrm{Ti}_{4}-\mathrm{NaY}$ up to $75 \%$ compared to that of $\mathrm{Ti}_{4}-\mathrm{NaY}$ with decolorization efficiency of $50 \%$ could be ascribed to the increasing number of Fe (III) active sites on the surface of the catalyst. The higher Fe loading occupied at the external surface of zeolite, the higher Fe ability to inhibit the $\mathrm{e}^{-}-\mathrm{h}^{+}$ recombination generated from the irradiated encapsulated $\mathrm{TiO}_{2}$. As such, the reduction in the energy gap of the catalyst after the loading of $\mathrm{Fe}$ (III) led to enhancement of the catalytic activity.
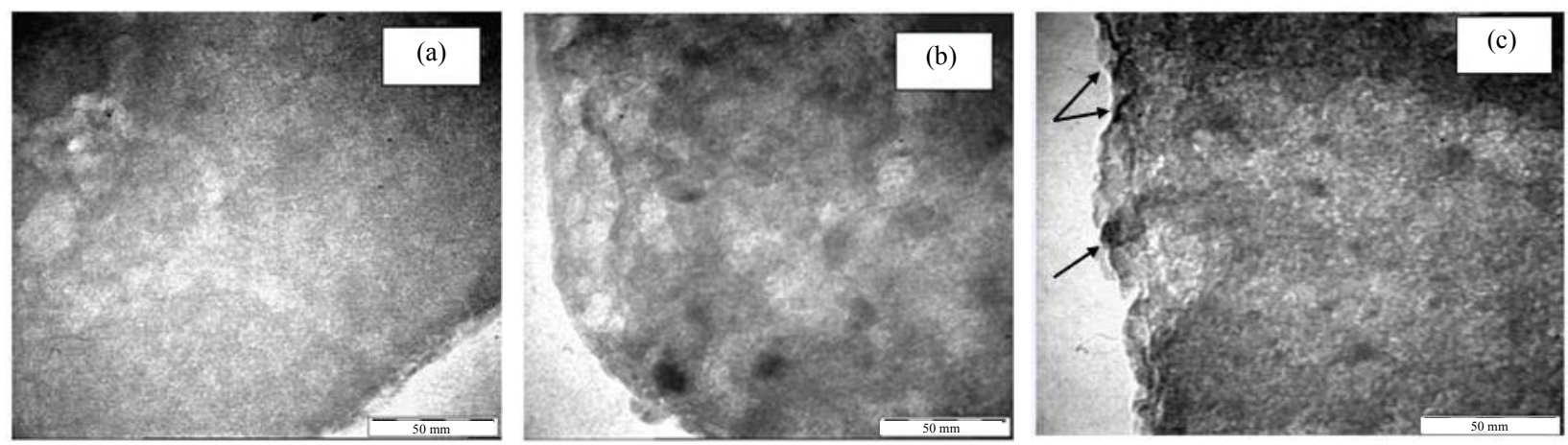

Figure 2. The TEM images of $\mathrm{NaY}(\mathrm{a}), \mathrm{Ti}_{4}-\mathrm{NaY}$ (b) and (c) $0.8 \% \mathrm{Fe}^{\mathrm{T}} \mathrm{Ti}_{4}-\mathrm{NaY}$. 


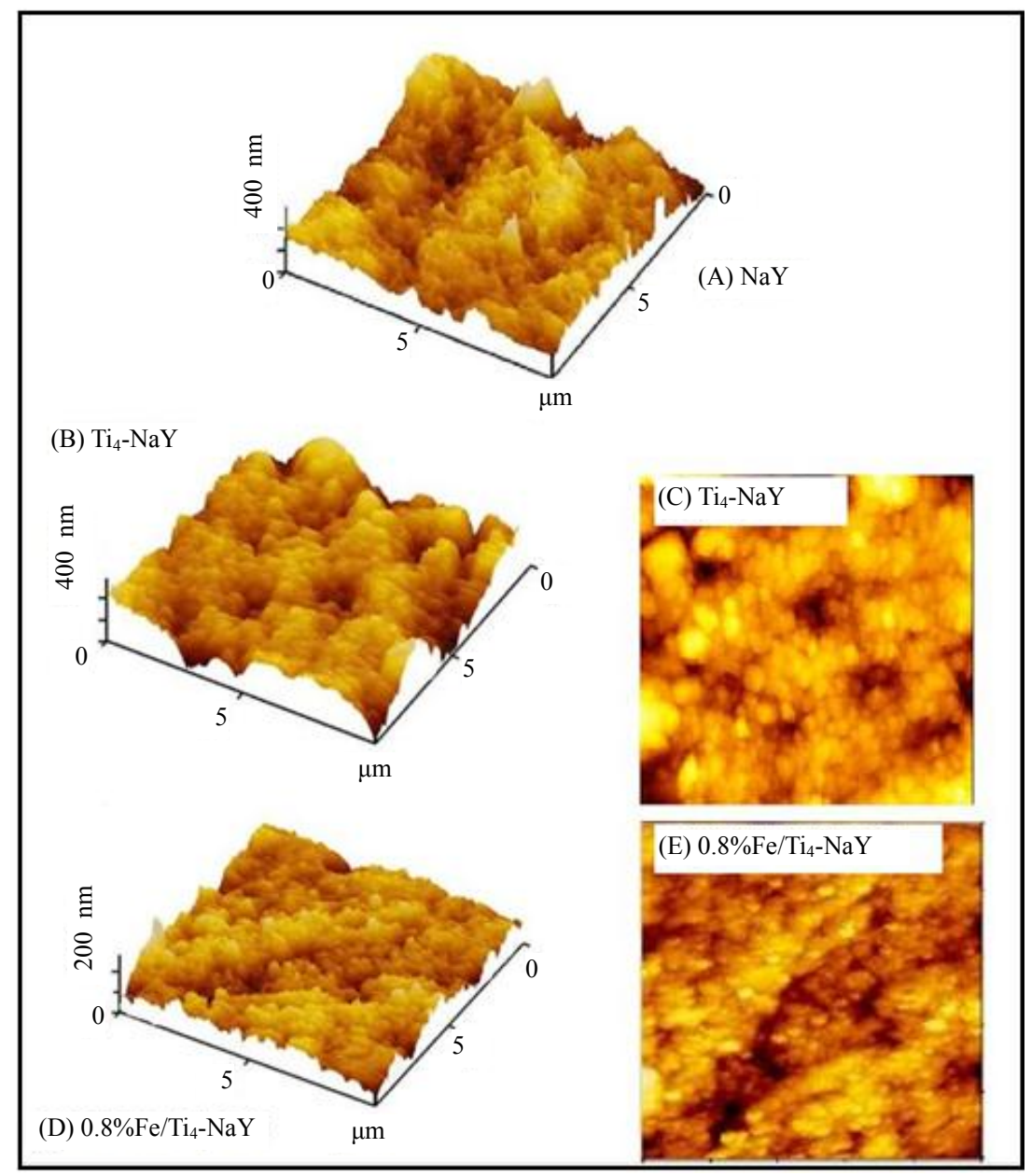

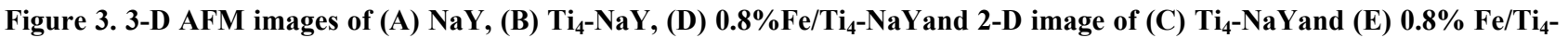
NaY.

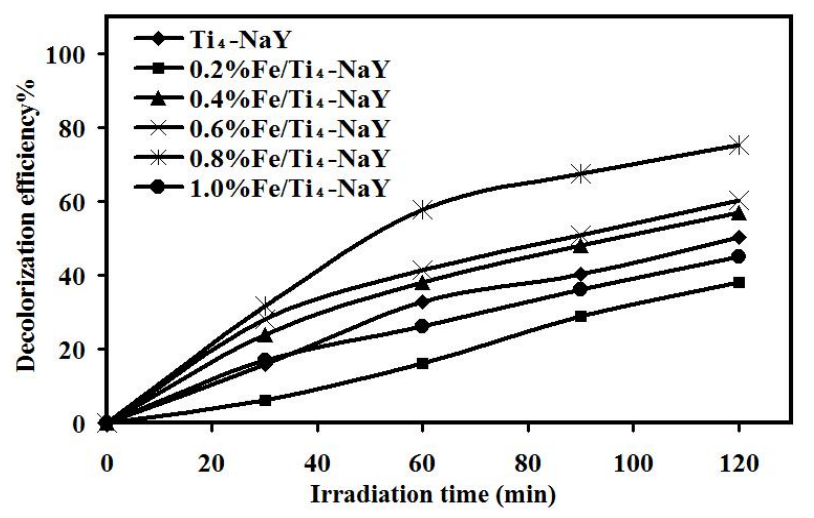

Figure 4. The effect of Fe loading on decolorization efficiency of amaranth $(10 \mathrm{ppm}$ initial dye concentration, original pH 5.5 and $1.5 \mathrm{~g} / \mathrm{l}$ catalyst loading without addition of $\mathrm{H}_{2} \mathrm{O}_{2}$ ).

The low activity of the catalyst below the optimum loading comparing with $0.8 \% \mathrm{Fe} / \mathrm{Ti}_{4}-\mathrm{NaY}$ was ascribed to the insufficient amount of Fe (III) ions in the reaction thus, the amount of $\mathrm{HO}^{\circ}$ radicals was not enough to de- graded the amaranth dye molecules.

In contract, with increasing the loading of Fe (III) to 1 $\mathrm{wt} \%$, a reduction in decolorization efficiency to $45 \%$ was observed which is ascribed to the increase in the recombination rate of $\mathrm{e}^{-}-\mathrm{h}^{+}$produced from the encapsulated $\mathrm{TiO}_{2}$. Choi et al., [20] reported that the average distances between the trapping sites decreased with increasing the concentration of $\mathrm{Fe}$ loading. In addition, increasing the amount of $\mathrm{Fe}$ above the optimum value causes the scavenging of $\mathrm{OH}^{*}$ radicals and large consumption of $\mathrm{H}_{2} \mathrm{O}_{2}$ [21].

\section{Control Experiment}

A sonolysis and silent experiment wascarried out to ascertain that the color removal of the amaranth dye was truly sonocatalytic and not just due to sonolysis and/or due to ordinary adsorption. An aqueous solution of amaranth with initial dye concentration of $10 \mathrm{mg} / \mathrm{L}$ was mixed separately with $1.5 \mathrm{~g} / \mathrm{L}$ catalyst of $\mathrm{Ti}_{4}-\mathrm{NaY}, 0.8 \%$ Fe-NaY and $0.8 \% \mathrm{Fe} / \mathrm{Ti}_{4}-\mathrm{NaY}$ at ambient temperature for $120 \mathrm{~min}$ in the absence of ultrasonic irradiation and the 
$\mathrm{pH}$ of the dye around 5.5 was kept normal without any prior adjustment. The results in Figure 5 indicated that no color removal was obtained after $120 \mathrm{~min}$ of continuous stirring for both catalysts $\left(\mathrm{Ti}_{4}-\mathrm{NaY}\right.$ and $0.8 \% \mathrm{Fe} / \mathrm{Ti}_{4}-$ $\mathrm{NaY}$ ). On the other hand, the degradation of the amaranth by ultrasound alone in the absence of catalyst was only $12 \%$ under the same reaction conditions of $10 \mathrm{mg} / \mathrm{L}$ of initial dye concentration, and original $\mathrm{pH}$ of 5.5. This low activity of the ultrasonic decolorization was ascribed to the insufficient amount of $\mathrm{OH}^{*}$ radicals generated by ultrasonic alone since radicals in this case were generated only through the dissociation of water molecules.

A preliminary study for different heterogeneous catalysts i.e. $0.8 \% \mathrm{Fe} / \mathrm{NaY}, \mathrm{Ti}_{4}-\mathrm{NaY}$ and $0.8 \% \mathrm{Fe} / \mathrm{Ti}_{4}-\mathrm{NaY}$ was also performed in order to investigate the effect of mono-doping or co-doping of heterogeneous catalyst on the decolorization efficiency of amaranth in the presence of ultrasonic irradiation. The decolorization efficiency after $120 \mathrm{~min}$ of reaction was found to increase from $45 \%, 50 \%$ to $75 \%$ for $0.8 \% \mathrm{Fe} / \mathrm{NaY}, \mathrm{Ti}_{4}-\mathrm{NaY}$ and $0.8 \%$ $\mathrm{Fe} / \mathrm{Ti}_{4}-\mathrm{NaY}$, respectively.

The enhancement in the decolorization efficiency of amaranth from $45 \%$ to $75 \%$ was ascribed to the presence of active components i.e. $\mathrm{Ti}$ and $\mathrm{Fe}$ species into $\mathrm{NaY}$ which had the ability to generate more hydroxyl radicals during the ultrasonic reaction. In addition, the enhancement in the catalytic activity was ascribed to the higher number of active sites generated after the co-doping where both the internal and external surface area of zeolite were occupied by active components that increase the generation of the radicals during the reaction.

In order to enhance the decolorization efficiency of amaranth and increase the production of $\mathrm{OH}^{*}$ radicals during the reaction, the oxidizing agent i.e. $\mathrm{H}_{2} \mathrm{O}_{2}$ was added to the reaction solution in the presence of $0.8 \%$ $\mathrm{Fe} / \mathrm{Ti}_{4}-\mathrm{NaY}$ catalyst and the decoloriazation efficiency of amaranth was found to increase to $98 \%$ after the addition of $\mathrm{H}_{2} \mathrm{O}_{2}$. This enhancement in the decolorization efficiency was attributed to the generation of more $\mathrm{OH}^{-}$

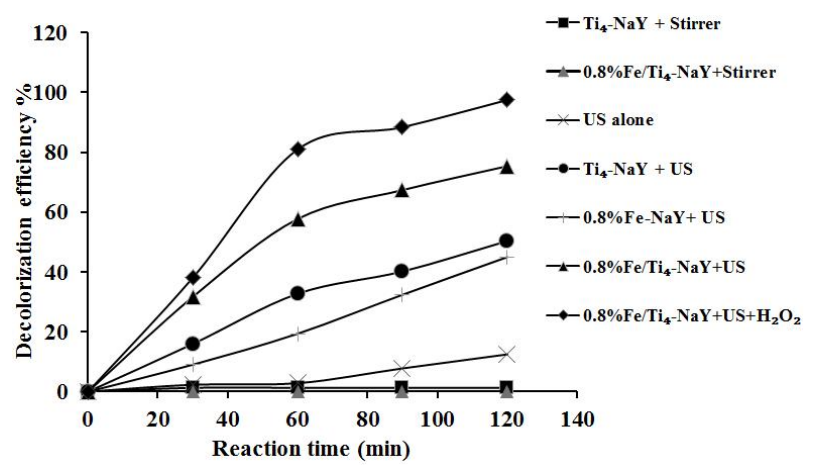

Figure 5. The decolorization efficiency of amaranth at different reaction conditions. radicals due to the disassociation of hydrogen peroxide into $\mathrm{H}^{*}$ and $\mathrm{OH}^{*}$ radicals in addition to the synergetic effect of the heterogeneous sonocatalyst.

\subsection{The Reusability and Stability of the Catalyst}

\section{Characterization of the Used Catalyst}

\section{1) $X R D$}

The XRD patterns of the heterogeneous catalyst of $\mathrm{Fe} / \mathrm{Ti}_{4}-\mathrm{NaY}$ for the fresh and used catalysts with calcination and without calcination are shown in Figure 6. From the figure, the fresh catalyst showed high crystallinity even after the loading of Ti species and Fe (III). The reflections $2 \theta$ values $12^{\circ}, 15^{\circ}, 18^{\circ}, 20^{\circ}, 23^{\circ}, 31^{\circ}$, and $34^{\circ}$ were attributed to the crystalline structure of $\mathrm{NaY}$. The values of these reflections were in agreement with those reported by Tayade et al. [12]. No new peaks could be found for the $\mathrm{TiO}_{2}$ or $\mathrm{Fe}_{2} \mathrm{O}_{3}$ which could be formed after the calcination step. The absence of these peaks could be due to the low amount of loading that resulted in unclear diffraction patterns. Xu and Langford [22] did not observeany peak corresponding to anatase $\mathrm{TiO}_{2}$ when they recorded an X-ray diffraction of a mechanical mixture of $56 \% \mathrm{TiO}_{2}$ P25 and zeolite. Castano et al. [23] suggest that the unclear diffraction lines for some metals might be attributed to either the formation of well-dispersed amorphous phases and/or the presence of crystals smaller than $4 \mathrm{~nm}$ that could not be detected by XRD.

After the using of the catalyst for three consecutive cycles, the intensities at $2 \theta 18.9^{\circ}, 20.6^{\circ}, 24.04^{\circ}$, and $31.9^{\circ}$ of the used catalyst were found to decrease for both the used catalysts with and without calcination in compareson with the fresh catalyst. This reduction in intensities could be ascribed to the partial destruction on the structure of the used catalyst recovered after the ultrasonic reaction. However, the structure of the used catalyst still showed high crystallinity even after three consecutive cycles.

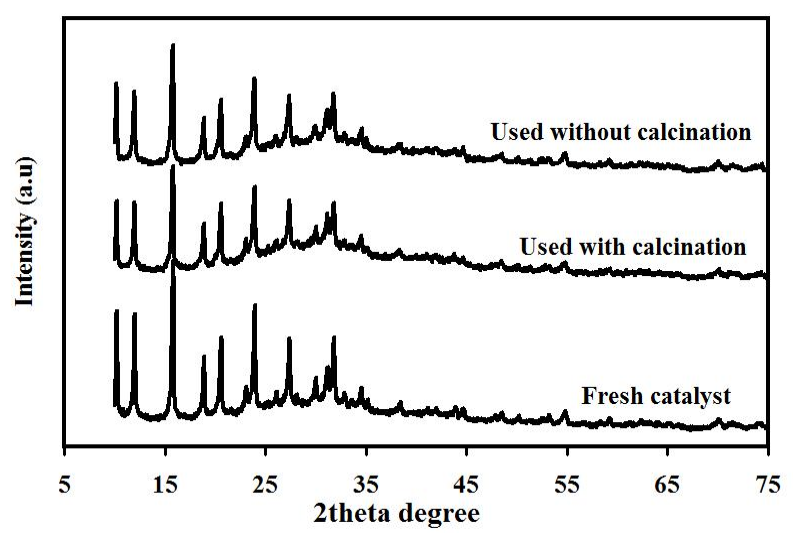

Figure 6. X-ray diffraction pattern of the fresh catalyst $0.8 \% \mathrm{Fe} / \mathrm{Ti}_{4}-\mathrm{NaY}$ and used catalyst with and without calcination. 


\section{2) SEM/EDAX}

The typical SEM image of the NaY support, fresh catalyst $0.8 \% \mathrm{Fe} / \mathrm{Ti}_{4}-\mathrm{NaY}$ and the reused catalyst with and without calcination are shown in Figure 7. As it noted in Figure 7(a), the structure of zeolite was tetrahedral and it remained the same after the loading of Ti and $\mathrm{Fe}$ ions as shown in Figure 7(b). The surface of the heterogeneous catalyst $\mathrm{Fe} / \mathrm{Ti}_{4}-\mathrm{NaY}$ was smooth without any agglomeration of metal oxide on it that can be formed after the calcination step. This could give an indication to the well dispersed of metal oxide on the solid support.

The reused catalyst, with and without calcination after three cycles of use was able to keep the similar structure of the fresh catalyst as shown in Figures 7(c) and (d). These results were in agreement with the results obtained from the XRD analysis for both the fresh and used catalyst and both types of used catalysts were able to keep their high crystallinity. This high crystalline structure was ascribed to the existence of zeolite support which is well known in its high stability and crystallinity.

The surface elemental analysis for the fresh and used catalyst such as $\mathrm{Si}, \mathrm{Al}, \mathrm{O}, \mathrm{Fe}$ and $\mathrm{Ti}$ was obtained by means of EDAX analysis in order to investigate the remaining element after three cycles of use. As shown in
Table 1, the Ti element was not detected at the surface since the titanium oxide was encapsulated inside the pores of zeolite. While the other element such as $\mathrm{Si}, \mathrm{Al}$ and $\mathrm{O}$ was considered as the main structure element of zeolite. However, the amount of Fe ions loaded on the fresh catalyst $0.8 \% \mathrm{Fe} / \mathrm{Ti}_{4}-\mathrm{NaY}$ was higher than the expected Fe content. This could be due to the non-homogeneous distribution of the metal at the surface of zeolite.

In spite of the exact amount remaining on the surface of the used catalyst, a slight reduction in the amount of Fe ions was indicated after three reusability cycles for the used catalyst with calcination and the remaining $\mathrm{Fe}$ at the catalyst surface was about $4.51 \mathrm{wt} \%$ while the remaining $\mathrm{Fe}$ after the three reusability cycles for the catalyst without calcination was $1.21 \mathrm{wt} \%$. These results can give an indication that the calcination step for the used catalyst after each run was important to maintain the stability of $\mathrm{Fe}$. Thus, the Fe was able to keep its stability on the surface of the catalyst despite the suffering from the low acidic condition of the reaction and the repeatability of using the catalyst.

\section{3) The Reusability Experiment}

The stability of the catalyst $0.8 \% \mathrm{Fe} / \mathrm{Ti}_{4}-\mathrm{NaY}$ after three consecutive cycles was studied to investigate the
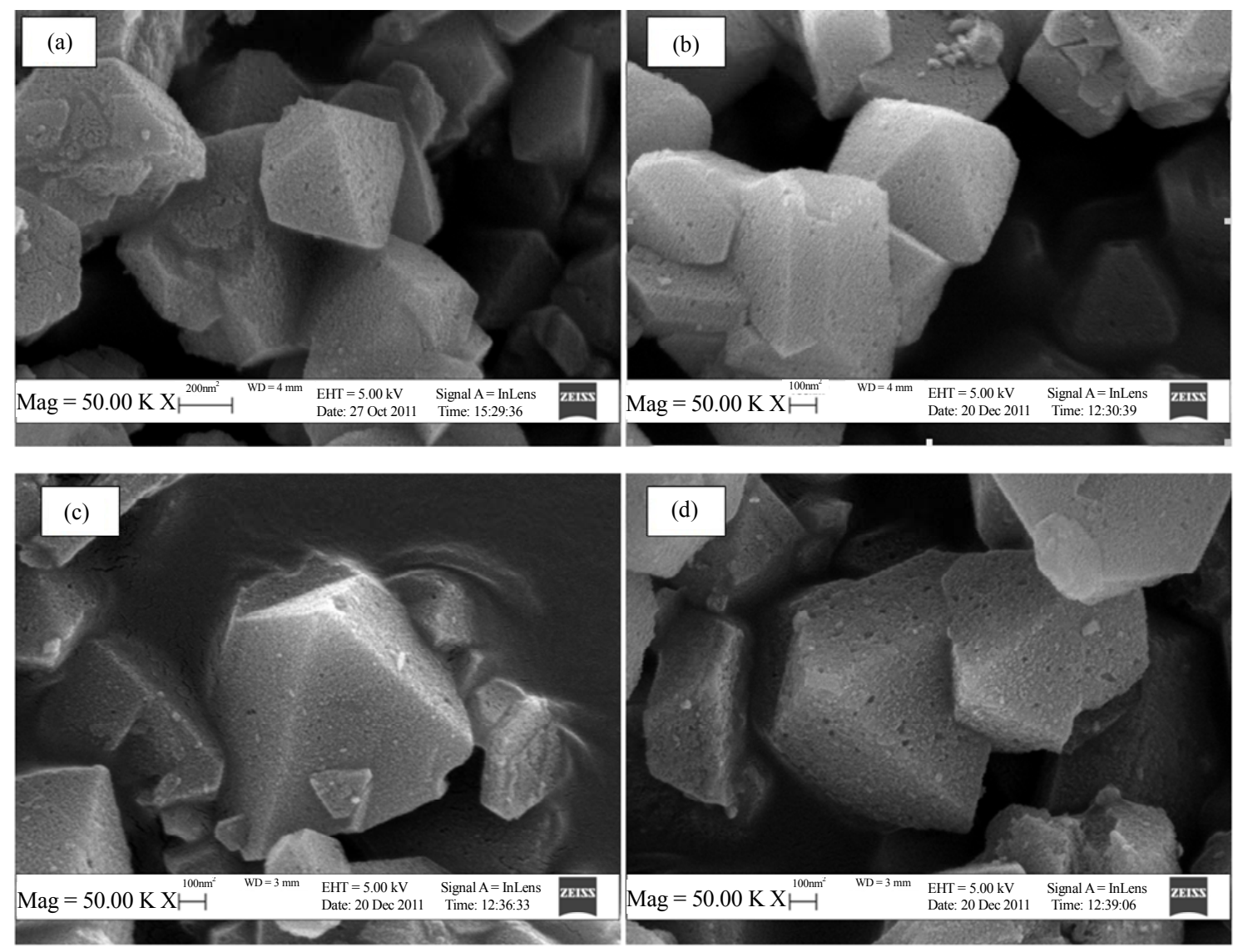

Figure 7. The surface morphology of the (a) $\mathrm{NaY}$ (b) $0.8 \% \mathrm{Fe} / \mathrm{Ti}-\mathrm{NaY}$ (c), (d) the used catalyst $0.8 \% \mathrm{Fe} / \mathrm{Ti}-\mathrm{NaY}$ with and without calcination respectively. 
Table 1. The chemical composition of the fresh catalyst $0.8 \% \mathrm{Fe} / \mathrm{Ti}_{4}-\mathrm{NaY}$ and used catalyst $0.8 \% \mathrm{Fe} / \mathrm{Ti}_{4}-\mathrm{NaY}$ with calcination and without calcination after three cycles of use for the decolorization of amaranth.

\begin{tabular}{cccc}
\hline Elements & \multicolumn{3}{c}{ Composition wt\% } \\
\hline & Fresh catalyst & $\begin{array}{c}\text { Used catalyst } \\
\text { with calcination }\end{array}$ & $\begin{array}{c}\text { Used catalyst } \\
\text { with calcination }\end{array}$ \\
$\mathrm{Si}$ & 46.09 & 45.49 & 51.42 \\
$\mathrm{Al}$ & 1.59 & 2.76 & 02.21 \\
$\mathrm{O}$ & 45.31 & 44.46 & 42.62 \\
$\mathrm{Fe}$ & 5.16 & 4.51 & 01.21 \\
$\mathrm{Ti}$ & - & - & - \\
\hline
\end{tabular}

decolorization activity after the use of the catalyst. The used catalyst with calcination was calcined at $500^{\circ} \mathrm{C}$ for 2 $\mathrm{h}$ after each run while the used catalyst without calcination was filtered, washed and dried at $80^{\circ} \mathrm{C}$ without any calcination step after each cycle. The reusability of the catalyst was checked for both the reuse catalyst with calcination and without calcination in three consecutive experiments by using fresh amaranth dye solutions at an optimum condition $10 \mathrm{ppm}$ dye concentration, $\mathrm{pH} 2.5,20$ mmol $\mathrm{H}_{2} \mathrm{O}_{2}$ and $2.0 \mathrm{~g} / \mathrm{L}$ catalyst. The results are as shown in Figure 8.

The decolorization efficiency of the fresh catalyst was $98 \%$ at the end of the reaction. However, after the reuse of the catalyst for three consecutive cycles, with and without calcination step, the activity was $97 \%$ and $94 \%$, respectively. This result indicated good activity and stability of the catalyst since there was no remarkable drop in decolorization efficiency comparing with the fresh catalyst. As it is known, Fe ions are affected extremely by the acidic condition of the reaction while Ti ions are more stable due to the presence of $\mathrm{Ti}$ ions inside the pores of zeolite which makes it difficult to abrase during the reaction [24]. Therefore, the leaching of ions was checked for Fe (III) by A.A.S at the end of reaction after each cycle of the reusability run. The results were shown in Table 2. Leaching of ions increased after each cycle for both the used catalyst with calcination and without calcination. However, it was clear that the leaching of Fe ions from reuse catalyst with calcination was lower than the reused one without calcination. This behavior could be affected by the preparation method for the catalyst.

Since the $\mathrm{Fe}$ ions adhered on the surface of the catalyst by the drying step using the wet impregnation method. Some of the Fe ions will leach into the reaction due to the presence of $\mathrm{HCl}$. However, the calcination step after each reuse cycle will enhance the stability of remaining ions on the surface of the catalyst thus reducing the leaching of $\mathrm{Fe}$ (III) from the surface of the catalyst. As a result, the calcination step for the used catalyst was

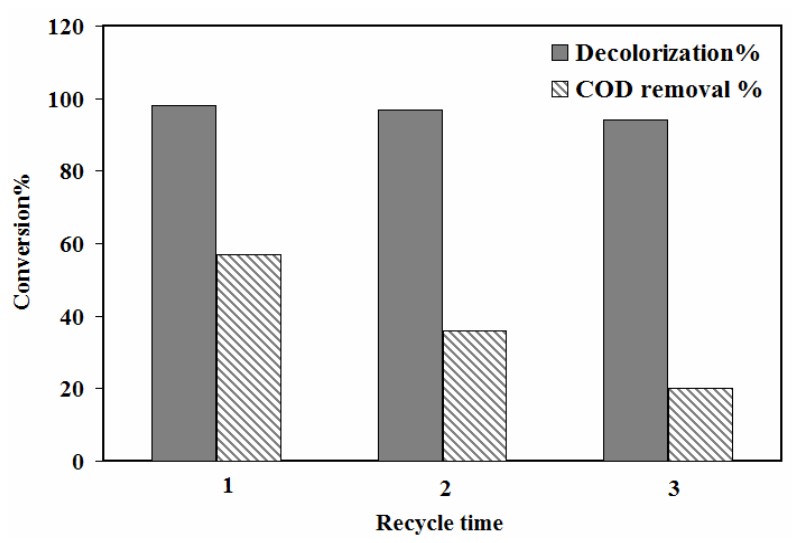

Figure 8. The decolorization efficiency and the COD removal of the fresh and used catalyst after three cycles usage.

Table 2. The leaching test for the reused catalyst measured by AAS.

\begin{tabular}{ccc}
\hline Cycle & \multicolumn{2}{c}{ leaching of Fe (III) in solution (ppm) } \\
\hline & Without calcination & With calcination \\
$1^{\text {st }}$ & 0.143 & 0.271 \\
$2^{\text {nd }}$ & 0.488 & 0.276 \\
$3^{\text {rd }}$ & 0.517 & 0.298 \\
\hline
\end{tabular}

important to maintain the activity of the catalyst by strengthening the stability of the Fe ions and yielding an active phase in its oxide state. Adding, the calcination step was important to remove the organic compound that might be formed on the surface of the catalyst during the reaction. Noorjahan et al. [25] also studied the reusability of the catalyst with and without calcination for the $\mathrm{Fe}$ (III)-HY catalyst in photo-phenton reaction and the results showed that the calcination step for the reuse catalyst gave the same activity as the fresh one and it has higher activity than the reuse catalyst without calcination. Kasiri et al. [26] reported that the leaching of $\mathrm{Fe}$ ions from the heterogeneous Fe-ZSM-5 was about $0.3 \mathrm{ppm}$ during the decolorizationof acid blue 74 .

In order to investigate the activity of the catalyst for the removal of organic compounds, the COD test was done for the experimental runs using fresh and used catalyst at $10 \mathrm{ppm}$ initial concentration of dye, normal $\mathrm{pH}$ about 5.5 and catalyst loading $2.0 \mathrm{~g} / \mathrm{l}$. The COD removal for the fresh catalyst was $57 \%$ while an appreciable reduction to $36 \%$ and $20 \%$ was observed after three cycles for the used catalyst with and without calcination respectively as shown in Figure 8. The reduction in the COD removal after three cycles reusability could be ascribed to the leaching of $\mathrm{Fe}$ ions from the surface of the catalyst that causes the decrease in the catalyst activity. However, the reused catalysts with calcination has shown 
better COD removal than the used one without calcination due to the higher Fe remaining on catalyst surface as shown in Table 2.

According to these results, it can be concluded that the heterogeneous catalyst $\mathrm{Fe} / \mathrm{Ti}-\mathrm{NaY}$ was stable catalyst since the possibility of the $\mathrm{TiO}_{2}$ leaching was not suggested due to its high stability and its position inside the pores of zeolite. On other hand, the amount of ions leached out from the support was small amount especially for the reusable catalyst with calcination step. Thus, the activity of the catalyst was mostly due to the presence of Fe ions in the heterogeneous catalyst rather than the trace exist in the reaction solution because of leaching. Panada et al., [27] have been suggested that the high stability and activity of the heterogeneous catalyst $\mathrm{Fe}_{2} \mathrm{O}_{3}-\mathrm{SiO}_{2}$ refer to the low amount of Fe leaching during the decolorization reaction of methyl orange.

\section{Conclusion}

A new heterogeneous catalyst was synthesized by loading two active metals, i.e. Ti and Fe (III) using an ion exchange and an impregnation method respectively. Different characterizations techniques were performed for the fresh and used catalysts. The results indicated that the catalyst showed high stability after three cycle of use while the leaching test showed that the amount of iron leached from the catalyst with calcination step was lower than that without calcination. The COD removal for the fresh catalyst was $57 \%$ while it reduced to $36 \%$ and $20 \%$ for the used catalyst with and without calcination step respectively. The hydrophilicity of the catalyst showed a slight increase compared to the non-modified support $\mathrm{NaY}$ due to the effect of loading Ti and Fe metals. As a result, this catalyst was highly potential in obtaining the high decolorization efficiency of amaranth while showing a small amount of leaching.

\section{Acknowledgements}

The Research University grant from Universiti Sains Malaysia to support this work is gratefully acknowledged.

\section{REFERENCES}

[1] C. G. Joseph, G. L. Puma, A. Bono and D. Krishnaiah, "Sonophotocatalysis in Advanced Oxidation Process: A Short Review," Ultrasonics Sonochemistry, Vol. 16, No. 5, 2009, pp. 583-589. doi:10.1016/j.ultsonch.2009.02.002

[2] N. Wang, L. Zhu, M. Wang, D. Wang and H. Tang, "Sono-Enhanced Degradation of Dye Pollutants with the Use of $\mathrm{H}_{2} \mathrm{O}_{2}$ Activated by $\mathrm{Fe}_{3} \mathrm{O}_{4}$ Magnetic Nanoparticles as Peroxidase Mimetic," Ultrasonics Sonochemistry, Vol. 17, No. 1, 2010, pp. 78-83.

doi:10.1016/j.ultsonch.2009.06.014
[3] D. H. Bremner, R. Molina, F. Martínez, J. A. Melero and Y. Segura, "Degradation of Phenolic Aqueous Solutions by High Frequency Sono-Fenton Systems (US- $\mathrm{Fe}_{2} \mathrm{O}_{3} / \mathrm{SBA}-$ 15- $\left.\mathrm{H}_{2} \mathrm{O}_{2}\right)$," Applied Catalysis B: Environmental, Vol. 90, No. 3-4, 2009, pp. 380-388. doi:10.1016/j.apcatb.2009.03.028

[4] X. Zhong, S. Royer, H. Zhang, Q. Huang, L. Xiang, S. Valange and J. Barrault, "Mesoporous Silica Iron-Doped as Stable and Efficient Heterogeneous Catalyst for the Degradation of C.I. Acid Orange 7 Using Sono-PhotoFenton Process," Separation and Purification Technology, Vol. 80, No. 1, 2011, pp. 163-171. doi:10.1016/j.seppur.2011.04.024

[5] A. N. Ökte and Ö. Yilmaz, "La and Ce Loaded $\mathrm{TiO}_{2-}$ ZSM-5 Catalysts: Comparative Characterization and Photocatalytic Activity Investigations," Microporous and Mesoporous Materials, Vol. 126, No. 3, 2009, pp. 245-252. doi:10.1016/j.micromeso.2009.06.013

[6] V. Mirkhani, S. Tangestaninejad, M. Moghadam, M. Habibi and A. Rostami-Vartooni, "Photocatalytic Degradation of Azo Dyes Catalyzed by Ag Doped $\mathrm{TiO}_{2}$ Photocatalyst," Journal of the Iranian Chemical Society (JICS), Vol. 6, No. 3, 2009, pp. 578-587. doi:10.1007/BF03246537

[7] N. A. Jamalluddin and A. Z. Abdullah, "Reactive Dye Degradation by Combined $\mathrm{Fe}(\mathrm{III}) / \mathrm{TiO}_{2}$ Catalyst and Ultrasonic Irradiation: Effect of Fe(III) Loading and Calcination Temperature," Ultrasonics Sonochemistry, Vol. 18, No. 2, 2011, pp. 669-678. doi:10.1016/j.ultsonch.2010.09.004

[8] J. Wang, Y. Lv, L. Zhang, B. Liu, R. Jiang, G. Han, R. $\mathrm{Xu}$ and $\mathrm{X}$. Zhang, "Sonocatalytic Degradation of Organic Dyes and Comparison of Catalytic Activities of $\mathrm{CeO}_{2} /$ $\mathrm{TiO}_{2}, \mathrm{SnO}_{2} / \mathrm{TiO}_{2}$ and $\mathrm{ZrO}_{2} / \mathrm{TiO}_{2}$ Composites under Ultrasonic Irradiation," Ultrasonics Sonochemistry, Vol. 17, No. 4, 2010, pp. 642-648. doi:10.1016/j.ultsonch.2009.12.016

[9] Y. L. Pang and A. Z. Abdullah, "Effect of Carbon and Nitrogen Co-Doping on Characteristics and Sonocatalytic Activity of $\mathrm{TiO}_{2}$ Nanotubes Catalyst for Degradation of Rhodamine B in Water," Chemical Engineering Journal, Vol. 214, 2013, pp. 129-138. doi:10.1016/j.cej.2012.10.036

[10] L. Zhu, Z.-D. Meng, C.-Y. Park, T. Ghosh and W.-C. Oh, "Characterization and Relative Sonocatalytic Efficiencies of a New MWCNT and CdS Modified $\mathrm{TiO}_{2}$ Catalysts and Their Application in the Sonocatalytic Degradation of Rhodamine B," Ultrasonic Sonochemistry, Vol. 20, No. 1, 2013, pp. 478-484. doi:10.1016/i.ultsonch.2012.08.005.

[11] A. N. Ökte and Ö. Yilmaz, "Characteristics of Lanthanum Loaded $\mathrm{TiO}_{2}-\mathrm{ZSM}-5$ Photocatalysts: Decolorization and Degradation Processes of Methyl Orange," Applied Catalysis A: General, Vol. 354, No. 1-2, 2009, pp. 132-142. doi:10.1016/j.apcata.2008.11.022

[12] R. J. Tayade, R. G. Kulkarni and R. V. Jasra, "Enhanced Photocatalytic Activity of $\mathrm{TiO}_{2}$-Coated NaY and HY Zeolites for the Degradation of Methylene Blue in Water," Industrial and Engineering Chemistry Research, Vol. 46, No. 2, 2007, pp. 369-376. doi:10.1021/ie060641o 
[13] X. Liu, K.-K. Iu and J. K. Thomas, "Encapsulation of $\mathrm{TiO}_{2}$ in Zeolite Y," Chemical Physics Letters, Vol. 195, No. 2-3, 1992, pp. 163-168. doi:10.1016/0009-2614(92)86129-6

[14] E. P. Reddy, L. Davydov and P. Smirniotis, " $\mathrm{TiO}_{2}$-Loaded Zeolites and Mesoporous Materials in the Sonophotocatalytic Decomposition of Aqueous Organic Pollutants: The Role of the Support," Applied Catalysis B: Environmental, Vol. 42, No. 1, 2003, pp. 1-11. doi:10.1016/S0926-3373(02)00192-3

[15] S. Easwaramoorthi and P. Natarajan, "Photophysical Properties of Phenosafranine (PHNS) Adsorbed on the $\mathrm{TiO}_{2}$ Incorporated Zeolite-Y," Microporous and Mesoporous Materials, Vol. 86, No. 1-3, 2005, pp. 185-190. doi:10.1016/j.micromeso.2005.07.009

[16] G. P. Joshi, N. S. Saxena, T. P. Sharma and S. C. K. Mishra, "Measurement of Thermal Transport and optical Properties of Conducting Polyaniline," Indian Journal of Pure and Applied Physics, Vol. 44, No. 10, 2006, pp. 786-790.

[17] J. Choi, H. Park and M. R. Hoffmann, "Effects of Single Metal-Ion Doping on the Visible-Light Photoreactivity of $\mathrm{TiO}_{2}$," Journal of Physical Chemistry C, Vol. 114, No. 2, 2010, pp. 783-792. doi:10.1021/jp908088x

[18] Y. Wu, J. Zhang, L. Xiao and F. Chen, "Preparation and Characterization of $\mathrm{TiO}_{2}$ Photocatalysts by $\mathrm{Fe}^{3+}$ Doping Together with $\mathrm{Au}$ Deposition for the Degradation of Organic Pollutants," Applied Catalysis B: Environmental, Vol. 88, No. 3-4, 2009, pp. 525-532. doi:10.1016/j.apcatb.2008.10.008

[19] I. Gúth and S. Lukic, "The Influence of Iron on the Optical Energy Gap in Glasses of Sb-SI Type," Journal of Optoelectronics and Advanced Materials, Vol. 3, No. 4, 2001, pp. 903-908.

[20] W. Choi, A. Termin and M. R. Hoffmann, "The Role of Metal Ion Dopants in Quantum-Sized $\mathrm{TiO}_{2}$ : Correlation between Photoreactivity and Charge Carrier Recombination Dynamics," The Journal of Physical Chemistry, Vol.
98, No. 51, 1994, pp. $13669-13679$. doi: $10.1021 / \mathrm{j} 100102 \mathrm{a} 038$

[21] N. A. Jamalluddin and Z. A. Ahmad, "Effect of pH and Catalyst Dosage on the Leaching of Fe from Fe (III) Doped Zeolite Y Used for Sonocatalytic Degradation of Acid Red B, " Research Journal of Chemistry and Environment, Vol. 15, No. 2, 2011, pp. 860-865.

[22] Y. Xu and C. H. Langford, "Enhanced Photoactivity of a Titanium (IV) Oxide Supported on ZSM5 and Zeolite A at Low Coverage," Journal of Physical Chemistry, Vol. 99, No. 29, 1995, pp. 11501-11507. doi:10.1021/j100029a031

[23] P. Castano, B. Pawelec, J. L. G. Fierro, J. M. Arandes and J. Bilbao, "Aromatics Reduction of Pyrolysis Gasoline (PyGas) over HY-Supported Transition Metal Catalysts," Applied Catalysis A: General, Vol. 315, 2006, pp. 101113. doi:10.1016/j.apcata.2006.09.009

[24] A. K. Kondru, P. Kumar and S. Chand, "Catalytic Wet Peroxide Oxidation of Azo Dye (Congo Red) Using Modified Y Zeolite as Catalyst," Journal of Hazardous MaTerials, Vol. 166, No. 1, 2009, pp. 342-347. doi:10.1016/j.jhazmat.2008.11.042

[25] M. Noorjahan, V. D. Kumari, M. Subrahmanyam and L. Panda, "Immobilized Fe(III)-HY: An Efficient and Stable Photo-Fenton Catalyst," Applied Catalysis B: Environmental, Vol. 57, No. 4, 2005, pp. 291-298. doi:10.1016/j.apcatb.2004.11.006

[26] M. B. Kasiri, H. Aleboyeh and A. Aleboyeh, "Degradation of Acid Blue 74 Using Fe-ZSM5 Zeolite as a Heterogeneous Photo-Fenton Catalyst," Applied Catalysis B: Environmental, Vol. 84, No. 1-2, 2008, pp. 9-15. doi:10.1016/j.apcatb.2008.02.024

[27] N. Panda, H. Sahoo and S. Mohapatra, "Decolourization of Methyl Orange Using Fenton-Like Mesoporous $\mathrm{Fe}_{2} \mathrm{O}_{3}$ $\mathrm{SiO}_{2}$ Composite," Journal of Hazardous materials, Vol. 185, No. 1, 2011, pp. 359-365. doi:10.1016/j.jhazmat.2010.09.042 